\title{
Prevalence and antibiotic sensitivity profile of urinary tract infection pathogens among pregnant and non pregnant women
}

\author{
S. I. OKORONDU ${ }^{1 *}$, C. O. AKUJOBI ${ }^{1}$, C. B. NNADI ${ }^{1}$, S. O. ANYADO-NWADIKE ${ }^{2}$ \\ et M. M. O. OKORONDU ${ }^{3}$
}

${ }^{I}$ Department of Microbiology, Federal University of Technology Owerri, P.M.B. 1526, Owerri, Nigeria.

${ }^{2}$ Department of Biotechnology, Federal University of Technology Owerri, P.M.B. 1526, Owerri, Nigeria.

${ }^{3}$ Department of Biochemistry, Federal University of Technology Owerri, P.M.B. 1526, Owerri, Nigeria.

*Corresponding author; E-mail: sokorondu@yahoo.co.uk

\begin{abstract}
The prevalence and antibiotic sensitivity profile of urinary tract infection isolates from 100 pregnant women attending antenatal clinic in Owerri General Hospital, Nigeria was assessed. The prevalence of UTI isolates from the pregnant women was compared with that in non-pregnant women. The organisms isolated include: Escherichia coli, Staphylococcus aureus, Coagulase negative Staphylococcus, Klebsiella spp, Pseudomonas spp, Proteus spp and Streptococcus spp. Antibiotic sensitivity pattern of the isolates were also determined using disk diffusion test. One hundred (100) women were tested; $40 \%$ had bacteriuria as against $31 \%$ in non-pregnant women. The most sensitive isolate was E. coli, while the least was Streptococcus spp. The most effective antibiotics were Gentamycin, Tarivid and Ciprofloxacin, while the least occurred with Chloramphenicol, Ampicillin, Septrin, Ampiclox. Improvement on personal hygiene and diagnostic screening and treatment will help to reduce the prevalence of bacteriuria in pregnancy. There is also the need for regular antibiotic survey as this will ensure up to date information on the usefulness of the various antibiotics to treat infection thereby avoiding drug resistance as a result of continuous usage of drugs that are not sensitive to some microorganisms.
\end{abstract}

Keywords: antibiotic sensitivity, urinary tract, bacteriuria, women, gram-positive, gram-negative.

\section{INTRODUCTION}

Urine is a waste product of metabolism in vertebrates including humans. When it accumulates in the body, it is stored temporarily in the urinary bladder before it is discharged from the body through the urethra. (Erick and Dick, 1996).The bladder and urinary tract are normally sterile. The urethra however may contain a few commensals and also perineum (wide variety of gram-positive and gram-negative organisms) which can contaminate urine when it is being collected (Schneider et al., 1996). With female patients, the urine may become contaminated with organisms from the vagina. Vaginal contamination is often indicated by the presence of epithelial cells and mixed bacterial flora (Asscher and Sussman, 1966).

Most urine specimens will contain fewer than $10^{4}$ contaminating organisms per $\mathrm{ml}$ provided the urine has been collected with care to minimize contamination before the 
commensals have had time to multiply significantly. The presence of bacteria in urine is called bacteriuria. It is usually regarded as significant when the urine contains $10^{5}$ organisms or more per $\mathrm{ml}$ of urine. Therefore, urinary tract infection (UTI) is caused by a variety of gram-negative and gram-positive bacteria that act as normal flora of some parts of the system and descend down into the urinary tract and when they get there, they cause urinary tract infections. Bacteria are the most primary organism that causes most UTI in human being. These bacterial agents are called urinary pathogen (uropathogens). The bacterial agents are grouped into aerobic gram-negative rods and the facultative anaerobic cocci. They include: Escherichia coli, Klebsiella spp, Enterobacter spp, Citrobacter spp, Proteus mirabilis, Pseudomonas aeruginosa, Alcaligenes spp, Acinetobacter spp, Staphylococcus aureus, (Muller et al., 2006). This infection may involve the urethra, ureters, the urinary bladder and the kidneys leading to diseases such as pylonephritis, urethritis, cystitis, bacteriuria and prostates (Mba et al., 2002). These syndromes tend to reduce the flow of urine along the urinary tract. The most common of them that dominate as the causative agent in all patients is the Escherichia coli that accounts for $80-90 \%$ of infections (Polk, 1979). Infection of the bladder is called cystitis. It causes frequency, dysuria (pain on passing urine), suprapubic pain, sometimes haematuria and usually pyuria (increased number of pus cells in urine). Infection of the kidney is called pyelonephritis. It causes loin pain, pyuria, rigors, fever and often bacteraemia (Millar et al., 1995). Risk of infection is increased when there is urine retention due to the bladder not emptying completely, or when urinary flow is obstructed due to renal stones, urinary schistosomiasis, enlarged prostate (commonest cause of recurring UTI in men) or tumour (Raz et al., 1993). Persistent or recurrent UTI can lead to renal failure. Other bacteria that cause UTIs include Pseudomonas, Proteus, Klebsiella spp, Staphylococcus aureus, and Staphylococcuss aprophyticus. They are associated with hospital-acquired infections often following catheterization or gynaecological surgery (Gould et al., 2010). Proteus spp infections are also associated with renal stones.

Urinary tract infections occur more frequently in women than in men due to the shortness of the female urethra (Nicolle, 2008). Symptomatic and asymptomatic UTI is common in pregnancy. Undetected, untreated, asymptomatic bacteriuria can lead to pyelonephritis later in pregnancy. Goplerud et al. (2000) observed that the flora of the cervix changes during pregnancy with a marked decrease in the number of anaerobes from the first to the third trimester and a rebound almost immediately postpartum. Whereas reagent strip analysis lacks the sensitivity to be used for asymptomatic bacteriuria screening, studies have shown that the presence of nitrites in the urine of symptomatic woman is strongly suggestive of significant bacteriuria (D'Souza et al., 2004). Treatment of asymptomatic bacteriuria in pregnant patients is important because of the increased risk of UTI and associated sequelae (Guinto et al., 2010).The following are measures that studies suggest may reduce the incidence of urinary tract infections. A prolonged course (six months to a year) of low-dose antibiotics usually nitroforantoin is effective in reducing the frequency of UTIs in those with recurrent UTIs (Nicolle, 2008). For postmenopausal women intravaginal application of topical estrogen cream can prevent recurrent cystitis (Jepson and Craig, 2008). This however is not as useful as low dose antibiotics (Nicolle, 2008). Studies have shown that breast feeding can reduce the risk of UTIs in infants (Hanson, 2004).

As a result of several hormonal and anatomical changes, pregnant women are at 
more risk to develop urinary tract infections (Nicolle, 2008). These changes alongside with an already short urethra that is closer to the anus (approximately $25-50 \mathrm{~mm}$ in females) compared to males with $20 \mathrm{~cm}$ and difficulty with hygiene due to a distended pregnant belly increases the frequency of UTI in pregnancy. A steady increase of resistance pattern to antimicrobials has been documented over the past years, it has been found out that the trend of antibiotic sensitivity pattern to various isolates usually changes with time and because of that, there is need to keep on running antibiotic sensitivity test that will be given in the treatment of a particular illness. Screening of pregnant women for UTI can minimize these UTI associated complications and adequate treatment and control of these conditions need a good knowledge of the bacteria species involved and their susceptibilities to antibiotics is very important.

This study therefore is to identify the pathogens responsible for UTI in pregnant women in Owerri, Nigeria, to check the prevalence of UTI between pregnant and nonpregnant women with age and to determine the susceptibility of the isolates to a variety of gram positive and gram negative antibiotics.

\section{MATERIALS AND METHODS}

Antibiotics disc used were obtained from the manufacturer; OPTUN LABORATORIES NIG. LTD and the manufacture and expiry dates were correctly checked. It includes the gram positive and gram negative Discs.

\section{Source of sample}

A total number of 100 samples were collected from pregnant women who came for their routine antenatal checkup in Owerri, Imo State, Nigeria. The samples used for this study were midstream urine gotten through the clean catch method.

\section{Urine analysis}

Analysis of each sample was carried out using a standard proprietary test strip (med combi9). The strip gives result for parameters such as $\mathrm{pH}$, Glucose, ascorbic acid, protein, nitrites, ketones, bilirubin, urobilinogen, blood, and colour. A test strip was dipped into each urine sample and gently removed from the sample. The back of the strip was wiped gently on the tip of the container. It was matched with the standard colour band on the product container labeled to read off the value for parameter.

\section{Microscopic examination of samples}

Each sample was homogenized and 1 $\mathrm{ml}$ poured into test tubes. The tubes were correctly balanced and placed inside a centrifuge and spun for 5-10 minutes. The supernatant fluid was decanted and the deposit mixed together. A drop of each deposit was placed on a clean grease free slide, covered with a cover slip and examined microscopically with low power (x10) and high power ( $x 40)$ objectives lens.

The presence of organism (yeast cell, Trichomonas virginalis), epithelial cell, pus cells and red blood cells were also noted.

\section{Bacteriological examination of samples}

The urine samples were examined bacteriologically using the techniques as described by Cheesbrough (2002). One milliliter of each urine sample was poured on a solid cled agar medium and spread evenly with a sterile glass rod. The plates were incubated at $37{ }^{\circ} \mathrm{C}$ for 24 hours and were examined for bacterial growth. The isolate were sub cultured on Nutrient agar medium, MacConkey agar and Blood agar medium by streaking techniques for characterization as described by Cheesbrough (2002). The plates were incubated for 24 hours at $37{ }^{\circ} \mathrm{C}$. They 
were stored in a refrigerator until required for identification test.

\section{Identification and characterization of the isolates}

The plates were incubated at $37{ }^{\circ} \mathrm{C}$ for 24 hours and examined for growth. The morphological characteristics of the colonies isolated were observed based on their pattern of growth, colour, size and shape. Other test carried out on the isolates include Gram stain reaction, motility (hanging drop method) and biochemical parameters identification testsidentification tests such as Catalase, Coagulase, Indole, Oxidase, Urease.

\section{Antibiotic sensitivity test}

The antibiotic susceptibility test was carried out using Disc diffusion method. It provides a simple and reliable test especially applicable in routine clinical bacteriology. Pure cultures of the isolates were used for antibiotic susceptibility. A discrete colony of each was inoculated on the surface of nutrient media using a sterile spreader to spread evenly. Commercially prepared selected gram-positive disc used were Ciproflox $10 \mu \mathrm{g}$, Norfloxacin $10 \mu \mathrm{g}$, Gentamycin $10 \mu \mathrm{g}$, Amoxil $20 \mu \mathrm{g}$, Streptomycin $30 \mu \mathrm{g}$, Rifampicin $20 \mu \mathrm{g}$, Erythromycin $30 \mu \mathrm{g}$, Ampiclox $20 \mu \mathrm{g}$, Levofloxacin $20 \mu \mathrm{g}$, Chloramphenicol $30 \mu \mathrm{g}$ and negative antibiotics used include Tarivid $10 \mu \mathrm{g}$, Ciproflox $10 \mu \mathrm{g}$, Augmentin $30 \mu \mathrm{g}$, Gentamycin $10 \mu \mathrm{g}$, Streptomycin $30 \mu \mathrm{g}$, Nalidixic acid $30 \mu \mathrm{g}$, Reflacin $10 \mu \mathrm{g}$, Ceporex $10 \mu \mathrm{g}$, Septrin $30 \mu \mathrm{g}$, Ampicillin $30 \mu \mathrm{g}$. They were placed on the surface of each inoculated plate. The plates were incubated at $37{ }^{\circ} \mathrm{C}$ for 24 hours and examined for growth inhibition. The bacterial isolate with clear zone were indicated as sensitive to the antibiotics while the isolates with no clear zone were indicated as resistant to the antibiotics. Also the clear zones of inhibition on each plate were measured using a pair of divider and a meter rule and recorded.

\section{RESULTS}

One hundred pregnant women urine were examined, 40 urine samples showed significant bacterial growth within 24 hours of incubation at a temperature of $37{ }^{\circ} \mathrm{C}$ while 60 samples showed no growth (Table 1)

Examination of the non-pregnant women that complained of symptomatic bacteriuria, out of 100 urine samples cultured, 31 samples showed significant bacterial growth while 69 showed no growth (Table 2). Bacteria isolated from both pregnant and nonpregnant women were: Escherichia coli, Klebsiella spp, Staphylococcus aureus, Coagulase negative Staphylococcus, Pseudomonas aeruginosa, Proteus spp, Streptococcus spp. Table 1 shows the different age distributions of pregnant women with asymptomatic bacteriuria. The highest growth occurred between the ages of 28-32 with 12 $(30.0 \%)$ isolates, while the least occurred between the ages of 33-37 with 5 (12.5\%) isolates. Table 2 shows the different age distributions of non pregnant women with symptomatic bacteriuria. The highest growth occurred between the ages of 38-42 with 6 $(19.35 \%)$ isolates, while the least occurred between the ages of $15-17$ with $1(0.03 \%)$ isolate. Table 3 shows the antibiotic sensitivity pattern of the urine isolates, from pregnant women. The isolates were tested with gram positive and gram negative antibiotic disks as the case may be and E. coli was shown to be highly sensitive to Tarivid, Gentamycin, Nalidixic acid, Reflacine and Ciproflox. Staphylococcus was highly sensitive to Ciproflox, Norfloxacin, Levofloxacin and Gentamycin. Klebsiella spp and Proteus spp were highly sensitive to Tarivid, Nalidixic acid and Gentamycin. Comparative analysis of the activities of Reflacin, Tarivid and Ciproflox revealed that Tarivid showed greater inhibitory effect 
against E. coli, Streptococcus spp, Proteus spp, Klebsiella spp than the Ciproflox, while Ciproflox exhibited a greater growth inhibitory effect on Staphylococcus spp, Pseudomonas spp, than Tarivid. Figure 1 shows the bacteria isolated from urine of pregnant women with their age distribution. The research showed that the most predominant organism were E. coli and Staphylococcus aureus and Coagulase negative staphylococcus which accounts for 12 (30.0\%), 7 (17.5\%) and 7 (17.5\%) respectively. While Klebsiella spp, Pseudomonas auruginosa, Proteus spp,
Streptoccoccus spp accounts for 5 (12.5\%), 4 $(10.0 \%), 3(7.5 \%), 2(5.0 \%)$ respectively. $E$. coli and Klebsiella spp ranked high between the ages of 28-32. Figure 2 shows the age distribution of pregnant and non-pregnant women with bacteriuria. Out of the 100 pregnant women examined, 40 were positive for UTI. While in non-pregnant women, 31 were positive for UTI. Pregnant women had their highest positive cases seen between the ages of 28-32 years with 12 (30\%) isolates compared to the non-pregnant women who had their highest isolates $6(19.4 \%)$ between the ages of $38-42$ years.

Table 1: Asymptomatic bacteriuria among pregnant women.

\begin{tabular}{lccc}
\hline Age (years) & Number examined & $\begin{array}{c}\text { Positive } \\
\text { (Growth) }\end{array}$ & $\begin{array}{c}\text { Negative } \\
\text { (No Growth) }\end{array}$ \\
\hline $15-17$ & 0 & 0 & 0 \\
$18-22$ & 9 & $6(15.0 \%)$ & $3(5.0 \%)$ \\
$23-27$ & 34 & $10(25.0 \%$ & $24(40.0 \%)$ \\
$28-32$ & 30 & $12(30.0 \%)$ & $18(30.0 \%)$ \\
$33-37$ & 12 & $5(12.5 \%)$ & $7(11.67 \%)$ \\
$38-42$ & 15 & $7(17.5 \%)$ & $8(13.33 \%)$ \\
$>43$ & 0 & 0 & 0 \\
Total & 100 & 40 & 60 \\
\hline
\end{tabular}

Table 2: Symptomatic bacteriuria among non pregnant women.

\begin{tabular}{lccc}
\hline \multicolumn{1}{c}{ Age (years) } & Number examined & $\begin{array}{c}\text { Positive } \\
\text { (Growth) }\end{array}$ & $\begin{array}{c}\text { Negative } \\
\text { (No Growth) }\end{array}$ \\
\hline $15-17$ & 4 & $1(0.03 \%)$ & $3(4.35)$ \\
$18-22$ & 16 & $5(16.13 \%)$ & $11(15.94 \%)$ \\
$23-27$ & 23 & $5(16.13 \%)$ & $18(26.09 \%)$ \\
$28-32$ & 21 & $5(16.13 \%)$ & $16(23.19 \%)$ \\
$33-37$ & 12 & $2(0.65 \%)$ & $10(14.49 \%)$ \\
$38-42$ & 17 & $6(19.35 \%)$ & $11(15.94 \%)$ \\
$43-48$ & 4 & $4(12.90 \%)$ & $0(0 \%)$ \\
$49-53$ & 0 & $0(0 \%)$ & $0(0 \%)$ \\
$>54$ & 3 & $3(9.68)$ & $0(0 \%)$ \\
Total & 100 & 31 & 69 \\
\hline
\end{tabular}


Table 3: Urine isolates from pregnant women and their antibiotic sensitivity pattern.

\begin{tabular}{|c|c|c|c|c|c|c|c|c|c|c|c|c|c|c|c|c|c|c|}
\hline \multirow{3}{*}{ Organisms } & \multirow{3}{*}{$\begin{array}{c}\text { Number } \\
\text { of } \\
\text { isolates }\end{array}$} & \multicolumn{17}{|c|}{ Number of isolates sensitive to Antibiotics } \\
\hline & & \multicolumn{3}{|c|}{$\begin{array}{c}\text { Broad } \\
\text { Spectrum } \\
\text { Antibiotics }\end{array}$} & \multicolumn{7}{|c|}{ Gram -negative Disk Antibiotics } & \multicolumn{7}{|c|}{ Gram-positive Disk Antibiotics } \\
\hline & & CPX & $\mathbf{C N}$ & $\mathbf{S}$ & OFX & PEF & $\mathbf{A U}$ & CEP & NA & SXT & $\mathbf{P N}$ & NB & AML & RD & $\mathbf{E}$ & LEV & APX & $\mathbf{C H}$ \\
\hline E. coli & 12 & 9 & 10 & 3 & 12 & 10 & 8 & 6 & 11 & 3 & 5 & NT & NT & NT & NT & NT & NT & NT \\
\hline Klebsiella spp & 5 & 2 & 4 & 1 & 5 & 4 & 3 & 3 & 4 & 1 & 2 & NT & NT & NT & NT & NT & NT & NT \\
\hline S. aureus & 7 & 6 & 6 & 5 & NT & NT & NT & NT & NT & NT & NT & 7 & 3 & 5 & 4 & 6 & 4 & 3 \\
\hline$C$-ve Staph & 7 & 7 & 5 & 5 & NT & NT & NT & NT & NT & NT & NT & 6 & 3 & 5 & 6 & 7 & 5 & 3 \\
\hline Pseudomonas spp & 4 & 3 & 3 & 1 & 2 & 2 & 2 & 1 & 1 & 1 & 1 & NT & NT & NT & NT & NT & NT & NT \\
\hline Proteus spp & 3 & 1 & 2 & 1 & 3 & 2 & 3 & 2 & 3 & 1 & 1 & NT & NT & NT & NT & NT & NT & NT \\
\hline Streptococcus spp & 2 & 1 & 1 & 2 & 2 & NT & NT & NT & NT & NT & NT & 2 & 1 & 2 & 1 & 2 & 1 & 0 \\
\hline
\end{tabular}




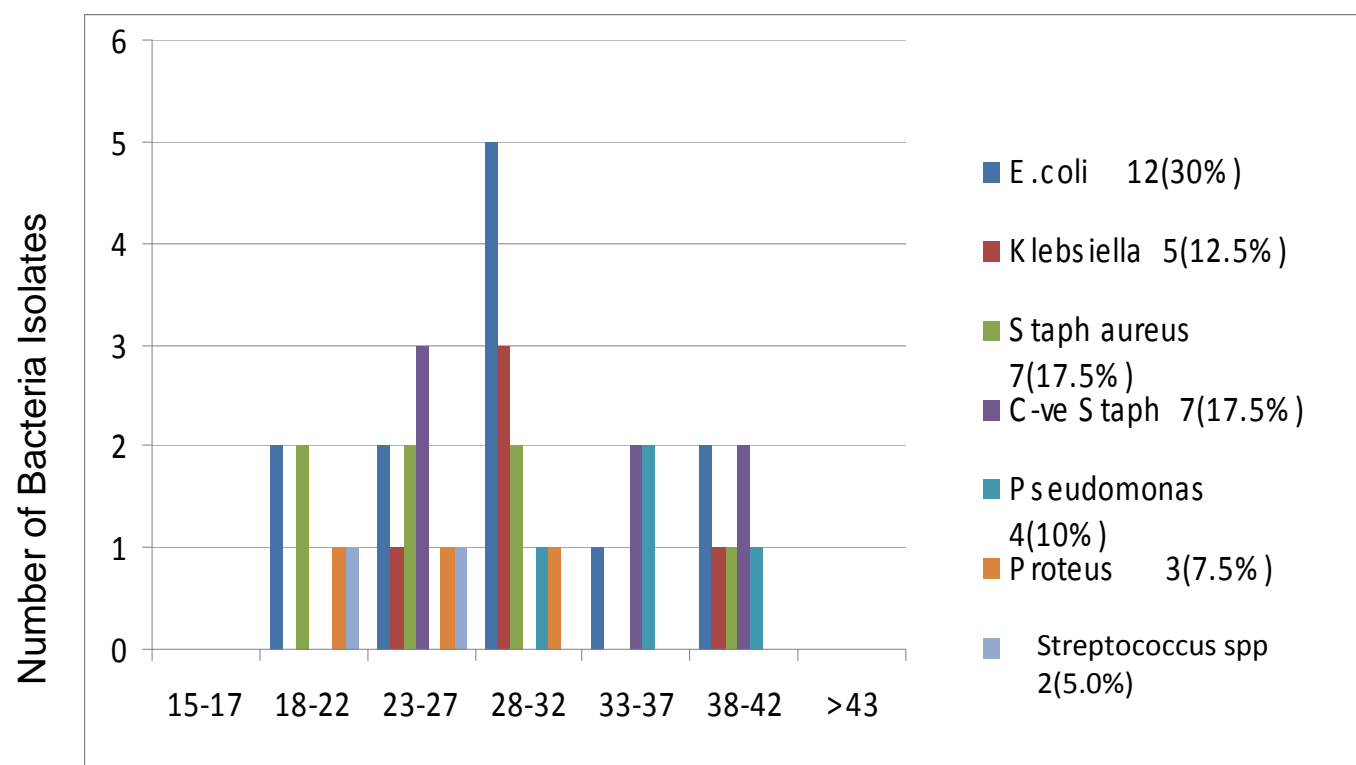

\section{Age distribution (years)}

Figure 1: Age distribution of bacteria isolated from urine of pregnant women with asymptomatic bacteriuria.

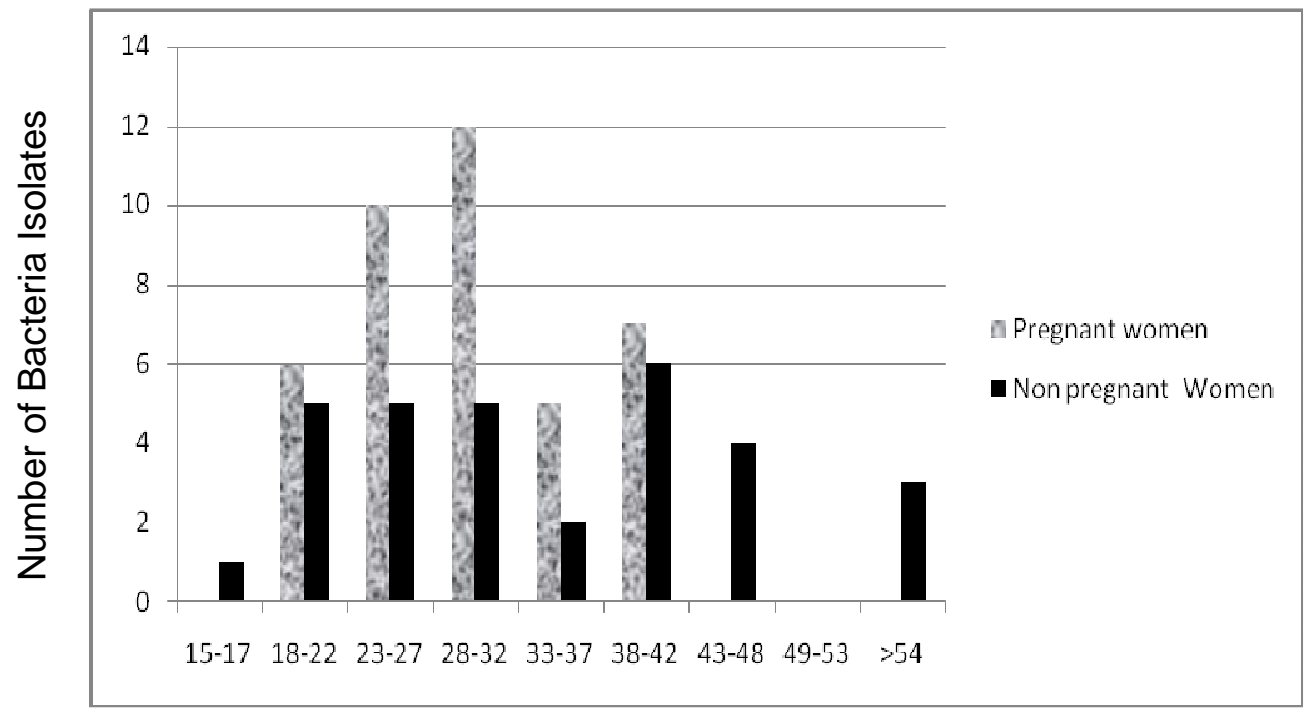

Age distribution (years)

Figure 2: Age distribution of bacteriuria between pregnant and non pregnant women. 


\section{DISCUSSION}

The main findings of this study were the prevalence of UTI among pregnant women in Owerri, Imo State of Nigeria which was $40 \%$ compared to the non-pregnant women that gave $31 \%$. Akerele et al. (2004) reported an incidence of $86.6 \%$ of bacteriuria among pregnant women in Benin City of Nigeria. On the same study, Mba et al. (2002) reported a high incidence rate of $54 \%$ of bacteriuria among pregnant women in Abia state of Nigeria. Perhaps the susceptibility to UTI during the period of pregnancy may be due to urethral dilation which started as early as 6 weeks and reaching the maximum during 22 - 24 weeks (Dalzell and Lefevre, 2000). Other factors like low socioeconomic status, difficulty in maintaining hygiene as a result of the distended pregnant belly, depressed immune system and also the hormonal and anatomical changes which leads to increase in urinary amino acids and urethral dilation have been observed as risk factors for UTI during pregnancy.

The highest isolates that occurred between the ages of 28-32 years in pregnant women could be attributed to these set of age being the most sexually active age of life when most women tend to give birth to their children before menopause sets in. Escherichia coli accounted for $12(30 \%)$ and Staphylococcus aureus 7 (17.5\%) as the predominant organisms among pregnant women may be attributed to the strains of $E$. coli that possess a variety of virulence characteristics that facilitate intestinal carriage, persistence in the vagina and then ascension and invasion of the anatomically normal urinary tract. This spectrum of organism isolated agrees with the predominance of $E$. coli in UTI (Katarzyuna, 2001; Mba et al., 2002; Akerele et al., 2004). Although $S$ aureus was known for years as rare urinary isolate, recently it has been reported to be the most frequent pathogen among pregnant women in Nigeria (Akinleye et al., 2006). In this setting, it was found the second most prevalent bacteria. Staphylococcus aureus is a bacterium that can be gotten from anywhere. It is a normal flora of the skin in our body. One can contact it by not observing good hygiene and through sexual intercourse.

The antibiotic sensitivity pattern of each of the isolates revealed that a large number of the organisms isolated in this study were sensitive to Tarivid (Ofloxacin), Nalidixic acid, Gentamycin, Ciprofloxacin, Norfloxacin. Very few isolates were sensitive to Ampicillin, Septrin, Chloramphenicol, Ampiclox which are very common and often purchased without prescription. The isolates that were highly sensitive to Gentamycin, Ciproflox, Tarivid, Nalidixic acid, Nofloxacin indicates that these drugs are still a useful urinary antiseptic in our environment. And this finding is comparable to reports on antimicrobial sensitivity pattern of isolates from various centers in the country (Ekweozor, 1996).

Ciproflox is quite expensive and therefore, not likely to be purchased, without prescription. Gentamycin is cheap and effective but requires parenteral administration and therefore, will not be suitable for treating out patients. Resistance of the isolates to some of the antibiotics is not only due to drug abuse, it could be also due to their vulnerable cell wall that is protected by an outer membrane that prevents permeation of the antibiotics.

\section{Conclusion}

Escherichia coli was the most prevalent causative organism in this research. Also asymptomatic bacteriuria in pregnant women is more prevalent than symptomatic among non-pregnant women. Antibiotics such as 
Tarivid, Gentamycin, Ciprofloxacin, Nalidixic acid play a great role in the treatment of urinary tract infection. Drug abuse which has been a bane of our society and enabling factor to antibiotic resistance should be a target source to save these newly developed antibiotics from suffering ineffectiveness. It is therefore recommended that urine for screening and diagnosis purpose should be carried out before the administration of antibiotics. Finally, the Federal Ministry of Health of Nigeria should enlighten women through antenatal lectures, radio and television health programs by qualified nurses and doctors especially the pregnant women on signs, symptoms, causes and control methods to prevent this urinary tract infection as majority of the women do not know the hygienic way of cleaning up after visiting the toilet to avoid pushing in the bacteria normally found in the feces into the urinary tract.

\section{REFERENCES}

Akerele J, Abhulimen F, Okofua. 2004. Prevalence of asymptomatic bacteria among pregnant women in Benin City. Nigeria Journal of Obsterics and Gynaecology, 2:141-144.

Akinyole O, Ogbolu DO, Akinyole OM, Terry OA. 2006. Asymptomatic bacteriuria of pregnancy in Ibadan, Nigeria: a re-assessment. Br. J. Biomed. Sci., 63 (3): 109-112.

Asscher AW, Sussman M, Waters WE, Davis RH, Chick S. 1996. Urine as a medium for bacterial growth. Lancet, 2: 10371041.

Cheesbrough M. 2002. District Laboratory Manual for Tropical Countries. Cambridge University Press: Cambridge, United Kingdom; 105-115.
Dal Zell JE, Lefevre ML. 2000. Urinary tract infection of pregnancy. Am. Acad. of Fam. Physicians, 60(3): 713-721.

D' Souza Z, D' Souza D. 2004. Urinary tract infection during pregnancy: dipstick urinalysis vs. Culture and Sensitivity. Obstet. Gynaecol., 24: 22 - 24.

Eric TH, Dick RC. 1996. Textbook of Therapeutics Drug and Disease Management $\left(6^{\text {th }}\right.$ edn). William and Willikins Publisher: USA; 1307-1323

Ekweozor CC, Onyemenem TN. 1996. Urinary tract infections in Ibadan: Causative organisms and antimicrobial sensitivity patterns. Afr. J. Med. Sci., 25: 165-169.

Guinto VT, Guia B, Festin MR, Dowswell T. 2010. Different antibiotic regimens for treating asymptomatic bacteriuria inpregnancy. Cochrane Database System Rev., 9: CD007855.

Goplerud CP, Ohm MJ, Galask. 2000. Floral of the cervix during pregnancy. Am. J. Obster. Gynaecol., 126: 858 - 865.

Gould CV, Umschccid CA, Agarwal RK, Kuntz G, Pegues DA. 2010. Guideline for prevention of catheter - associated Unriary tract infection. Infect. Control Hosp. Epidemiol., 31(4): 319 - 326.

Hanson LA. 2004. Protective effects of Breast feeding against urinary tract infection. Acta Paediatr., 93: 154-156.

Jepson RG, Craig JC. 2008. Cranberries for preventing UTI. Cochrane Database Syst. Rev., 1: CD001321.

Katarzyuna H, Katazyna S, Agnieszka S, Katryzma B, Waleria H. 2001. Antibiotic susceptibility of bacterial strains isolated from urinary tract infections. $J$. Antimicrob. Chemotherapy., 6: 773.

Mba LEK, Aluka C, Amadi AN. 2002. Bacterial agents associated with urinary tract infection in pregnancy. Journal of Hygiene and Sanitation, 2: 27-29. 
Millar LK, Wing DA, Paul RH. 1995.

Outpatient treatment of pyelonephritis in pregnancy: A randomized controlled trial. Obstet. Gynecol, 86: 560-564.

Muller L, De Buque L, Leialoha C, Grandinetti A, Killen J. 2006. Rapid enzymatic urine screening test to detect bacteriuria in pregnancy. Obstet. Gynaecol., 95: 601- 604.

Nicolle LE. 2008. Uncomplicated urinary tract Infection in adults including uncomplicated pyelonephritis. Urol. Clin. North. AM., 35 (1): 1-12.

Polk BF. 1979. Urinary tract infection in pregnancy. Clin. Obstet. Gynecol., 22: 285-292.
Raz, Raul, Stamm, Walter E. 1993. A controlled trial of intravaginal estriol in post menopausal woman with recurrent urinary tract infections. New England Journal of Medicine, 329(11): 753-756.

Schneider PF, Riley TV. 1996. Staphylococcus Saprophiticcus urinary tract infections: epidemiological data from Western Australia. Eur. J. Epidemiol., 12: 51-54. 